(2015). From theory use to theory building in learning analytics: A commentary on "Learning Analytics to Support Teachers during Synchronous CSCL". Journal of Learning Analytics, 2(2), 163-168. http://dx.doi.org/10.18608/jla.2015.22.12

\title{
From Theory Use to Theory Building in Learning Analytics: A Commentary on "Learning Analytics to Support Teachers during Synchronous CSCL"
}

\author{
Bodong Chen \\ University of Minnesota, USA \\ chenbd@umn.edu
}

\begin{abstract}
In this commentary on Van Leeuwen (2015, this issue), I explore the relation between theory and practice in learning analytics. Specifically, I caution against adhering to one specific theoretical doctrine while ignoring others, suggest deeper applications of cognitive load theory to understanding teaching with analytics tools, and comment on issues with theory building in the nascent field of learning analytics.
\end{abstract}

Keywords: learning theory, learning analytics, theory building

\section{INTRODUCTION}

This special issue on Learning Analytics and Learning Theory is timely and intended to demonstrate "(1) the ways in which learning theories are being used to craft analytics, (2) how analytics have helped us advance learning theories, and (3) the initial development of theories of learning with analytics" (see the Call for Papers). Van Leeuwen (2015), which I discuss here, is especially relevant to the first and third goals, introducing a suite of learning analytics to support teacher regulation in computer-supported collaborative learning ( $\mathrm{CSCL}$ ). The article uses cognitive load theory to explain how analytics are used by teachers, and proposes a model to encapsulate these uncovered mechanisms.

The word theory has several meanings. The Oxford dictionary defines it as "a supposition or a system of ideas intended to explain something" (e.g., Darwin's theory of evolution, Marx's theory of history); "a set of principles on which the practice of an activity is based" (e.g., a theory of teaching); or "an idea used to account for a situation or justify a course of action" (e.g., my personal theory that the achievement gap relates to poverty). Taken together, a theory explains how things work, predicts outcomes given certain conditions, and/or guides courses of action. The importance of theory does not need lengthy justification: theory building drives the growth of scientific knowledge (Popper, 2002); social theories provide frameworks for interpreting social phenomena and inspiring actions (Callinicos, 1999); learning theories explain how learning occurs and inform teaching, learning, and the design of learning environments (Bransford, Brown, \& Cocking, 2000).

Theory is often contrasted with practice in the sense that practice concerns doing or the actual application of theories. Despite learning analytics' emphasis on the practical side of measuring, collecting, analyzing, and reporting educational data (Long \& Siemens, 2011, p. 34), theory has been an important concern ever since the emergence of the field. One popular conception is that analytics 
(2015). From theory use to theory building in learning analytics: A commentary on "Learning Analytics to Support Teachers during Synchronous CSCL”. Journal of Learning Analytics, 2(2), 163-168. http://dx.doi.org/10.18608/jla.2015.22.12

"borrows" from learning theory to inform decision-making in data analytics and interpretation. Hence, thoughtful learning analytics research makes explicit adopted theories - theories of learning, pedagogy, epistemology, assessment, etc. (Knight, Buckingham Shum, \& Littleton, 2014; Suthers \& Verbert, 2013). Another rising notion is that analytics could in turn give rise to new theoretical advances in learning; for instance, to better explain tinkering in novice programming (Berland, Martin, Benton, Petrick Smith, \& Davis, 2013). Indeed, learning analytics is not merely the accepting side of a "one-way bridge;" rather, its advancements shed light on learning theory and lead to theory building of its own. The Van Leeuwen (2015) article represents an example of such work - it is contextualized in teacher regulation as a theory of teaching, grounded on cognitive load as a theory of cognition, and pregnant with new theories of teaching with analytics.

\section{THEORIES OF TEACHING AND LEARNING: REGULATION}

Learning analytics tools in Van Leeuwen (2015) attend to the issue of teacher regulation in synchronous CSCL processes. Drawing from a framework of collaborative learning in the classroom (Kaendler, Wiedmann, Rummel, \& Spada, 2015), this article conceptualizes teacher regulation as fostering, monitoring, and supporting student collaboration. This conception of a teacher's role and teacherstudent relations, despite no explicit exploration in this article, is consistent with scripting and classroom orchestration (Dillenbourg, 2013; Fischer, Kollar, Mandl, \& Haake, 2007) - teachers take major control over collaborative learning processes. Embracing this notion, Van Leeuwen (2015) naturally focuses on using analytics to support teacher's noticing and in-time intervening in CSCL processes, even if developed analytics might also very well be used by students.

The balance between teacher (external) and student (internal or self-) regulation has been extensively explored in literature (e.g., Simons \& Jong, 1992). Thoughtful adoption of learning theory in learning analytics research might involve acknowledging competing frameworks; in this case, the importance of the student's self-regulation. Compared to the claim that "teacher regulation of student activities can lead to improved group collaboration" (Van Leeuwen, 2015, p. 139), equally eloquent is an argument that students need to regulate themselves (Zimmerman, 1990) basically by performing teaching tasks described in Van Leeuwen (2015). An even stronger argument is that students ought to - and, as a matter of fact, can - take over higher levels of agency to define their own "proximal zone of development" (Scardamalia \& Bereiter, 1991). It is plausible that, in most cases, a learning analytic study demonstrates a fixation upon one camp of learning theory and neglects others. An open question for future "theory use" in learning analytics, though, is how to better deal with different theories concerned with the paradoxes of teaching and learning. As Burke puts it, "A way of seeing is also a way of not seeing" (1984, p. 49). Are we losing critical insights by adhering to one particular theory or a strand of theories? Is merely acknowledging theoretical stances enough for a learning analytics study? Do we need to go further to articulate why competing theories are less fruitful for a given scenario? 
(2015). From theory use to theory building in learning analytics: A commentary on "Learning Analytics to Support Teachers during Synchronous CSCL". Journal of Learning Analytics, 2(2), 163-168. http://dx.doi.org/10.18608/jla.2015.22.12

\section{THEORY OF COGNITION: COGNITIVE LOAD}

In Van Leeuwen (2015), cognitive load theory (Sweller, 1988) grounds the design and development of learning analytics. This article is situated in an existing CSCL environment that integrates group chat, cowriting, and source reading for ill-defined collaborative learning tasks. In this environment, the teacher could constantly monitor synchronous multi-group student activities. Cognitive load theory is well positioned to help us consider the daunting regulation task faced by teachers in this context. The information overload caused by online multimodal interactions makes it almost impossible for the teacher to keep track of all student activities in order to intervene in time. Cognitive load theory was properly applied to explain this issue and, more importantly, to guide the design of learning analytics tools to turn information overload into a digestible overview for the teacher.

The application of cognitive load theory in this context, however, could be furthered. One potentially fruitful direction is to elaborate the closely related concept of schema. According to schema theory, knowledge is stored in long-term memory not as sporadic facts but in the form of schemas that organize information necessary for solving a specific category of problems; through practice experts construct sophisticated schemas and thus have access to more and "different" knowledge than novices (Chi, Feltovich, \& Glaser, 1981). Even though working memory can hold only a limited number of items at a time (Miller, 1956), experts equipped with higher level schemas are capable of handling larger and more complex items in working memory and thus solving problems more effectively. Therefore, schema acquisition becomes important for reducing cognitive load. One interesting offshoot from Van Leeuwen's (2015) initial work, then, is whether teachers are constructing schemas from learning analytics use so that over time they get better at noticing critical moments to intervene. This direction recognizes agentic actions taken by teachers and is conducive to the important area of teacher development in learning analytics.

Another promising direction is to distinguish different types of cognitive load - i.e., intrinsic cognitive load (determined by the intrinsic nature of information), extraneous cognitive load (affected by the manner in which the information is presented), and germane cognitive load (reflecting the effort that contributes to constructing schemas and storing them into long-term memory) (Sweller, van Merrienboer, \& Paas, 1998). By distinguishing different types of cognitive load, we could explore their differentiated roles in the use of learning analytics. Efforts could be directed to understanding which learning phenomena might naturally cause higher intrinsic cognitive load, ensuring low extraneous cognitive load by crafting better feedback tools, and encouraging teachers to consciously construct schemas by increasing germane cognitive load. Moreover, given that information processing of different modalities is independent in working memory (Mayer \& Moreno, 2002), to what extent could we take advantage of this mechanism when designing learning analytics? 
(2015). From theory use to theory building in learning analytics: A commentary on "Learning Analytics to Support Teachers during Synchronous CSCL". Journal of Learning Analytics, 2(2), 163-168. http://dx.doi.org/10.18608/jla.2015.22.12

\section{TOWARDS THEORIES OF LEARNING ANALYTICS}

So far learning analytics researchers regard themselves largely as relevant adopters, if they adopt it at all, of learning theory. Well-intended dialogues remind the community of the importance of applying theory to inform learning analytics design. However, theory building of learning analytics remains scarce. More work needs to address the "middle space" between learning and analytics (Suthers \& Verbert, 2013), and develop theories of learning analytics' own in relation to existing and evolving theories from related domains. My biased view here is that theory building in learning analytics will determine the status of this field in the long run. Theory and practice should never be pitched against each other, or be separated by a chasm under a narrow bridge. "Good theory is practical precisely because it advances knowledge in a scientific discipline, guides research toward crucial questions, and enlightens the profession..." (Van de Ven, 1989, p. 486). In this regard, the model of teaching with analytics put forward by Van Leeuwen (2015), albeit preliminary, represents an important theorybuilding effort for the field. Other than the areas of refinement that I suggested above, Van Leeuwen has already made thoughtful plans to move forward: "Further research is required to validate the proposed mechanisms and to address questions such as how these mechanisms interact, which teacher characteristics must be taken into account, and what these mechanisms look like in authentic classroom situations" (p. 156).

However, I argue that for theory building within such a fledging field as learning analytics, attention should not be excessively turned to validity and verification. While valid knowledge is important for any field, plausibility and usefulness of a new theory should be even more emphasized here. Given the paradoxes of teaching and learning, scientific validation would be extraordinarily difficult to achieve for theories in learning analytics. As observed by Lindblom (1987), in social science, obsession with validity may suffocate the emergence of new theories or result in only trivial ones that are valid but explanatorily less powerful and unconducive to breakthroughs. At this point, we could try to grasp whatever understandings can be achieved about teaching or learning with analytics and focus on identifying their promise in leading towards better theories. Taking Van Leeuwen (2015) as an example, rather than fixing upon validating the proposed theory of teaching with analytics, one should also invest in the building part. Further theory building would focus on what could be built upon the proposed theory - e.g., a new speculation that teachers construct schemas when using analytics, better formulation of design parameters considering different types of cognitive load, or a testable hypothesis that students do not need teacher regulation if they had access to similar learning analytics. Here, coherence with other theories from relevant areas (Bereiter, 2014) - learning, teaching, computer algorithms, ethics and privacy, and so on - provides a wise alternative to validity for assessing theoretical contributions to the field of learning analytics.

\section{REFERENCES}

Bereiter, C. (2014). Principled practical knowledge: Not a bridge but a ladder. Journal of the Learning 
(2015). From theory use to theory building in learning analytics: A commentary on "Learning Analytics to Support Teachers during Synchronous CSCL". Journal of Learning Analytics, 2(2), 163-168. http://dx.doi.org/10.18608/jla.2015.22.12

Sciences, 23(1), 4-17. http://dx.doi.org/10.1080/10508406.2013.812533

Berland, M., Martin, T., Benton, T., Petrick Smith, C., \& Davis, D. (2013). Using learning analytics to understand the learning pathways of novice programmers. Journal of the Learning Sciences, 22(4), 564-599. http://dx.doi.org/10.1080/10508406.2013.836655

Bransford, J. D., Brown, A. L., \& Cocking, R. R. (2000). How people learn: Brain, mind, experience, and school (Expanded edition). Washington, DC: The National Academies Press.

Burke, K. (1984). Permanence and change: An anatomy of purpose (3rd ed.). Berkeley; Los Angeles, California: University of California Press.

Callinicos, A. (1999). Social theory: A historical introduction. Polity Press.

Chi, M. T. H., Feltovich, P. J., \& Glaser, R. (1981). Categorization and representation of physics problems by experts and novices. Cognitive Science, 5(2), 121-152.

Dillenbourg, P. (2013). Design for classroom orchestration. Computers \& Education, 69, 485-492. http://dx.doi.org/10.1016/j.compedu.2013.04.013

Fischer, F., Kollar, I., Mandl, H., \& Haake, J. M. (Eds.). (2007). Scripting computer-supported collaborative learning: Cognitive, computational and educational perspectives. New York: Springer.

Kaendler, C., Wiedmann, M., Rummel, N., \& Spada, H. (2015). Teacher competencies for the implementation of collaborative learning in the classroom: A framework and research review. Educational Psychology Review, 27(3), 505-536. http://dx.doi.org/10.1007/s10648-014-9288-9

Knight, S., Buckingham Shum, S., \& Littleton, K. (2014). Epistemology, assessment, pedagogy: Where learning meets analytics in the middle space. Journal of Learning Analytics, 1(2), 23-47. Retrieved from https://epress.lib.uts.edu.au/journals/index.php/JLA/article/view/3538

Lindblom, C. E. (1987). Alternatives to validity: Some thoughts suggested by Campbell's guidelines. Science Communication, 8(3), 509-520. http://dx.doi.org/10.1177/107554708700800305

Long, P., \& Siemens, G. (2011). Penetrating the fog: Analytics in learning and education. Educause Review, 46(5), 30-32.

Mayer, R. E., \& Moreno, R. (2002). Aids to computer-based multimedia learning. Learning and Instruction, 12(1), 107-119. http://dx.doi.org/10.1016/S0959-4752(01)00018-4

Miller, G. A. (1956). The magical number seven, plus or minus two: Some limits on our capacity for processing information. Psychological Review, 63(2), 81-97. http://dx.doi.org/10.1037/h0043158

Popper, K. (2002). Conjectures and refutations: The growth of scientific knowledge. London, UK: Routledge.

Scardamalia, M., \& Bereiter, C. (1991). Higher levels of agency for children in knowledge building: A challenge for the design of new knowledge media. Journal of the Learning Sciences, 1(1), 37-68. http://dx.doi.org/10.1207/s15327809jls0101/_3

Simons, P. R.-J., \& De Jong, F. P. C. M. (1992). Self-regulation and computer-aided instruction. Applied Psychology, 41(4), 333-346. http://dx.doi.org/10.1111/j.1464-0597.1992.tb00710.x

Suthers, D., \& Verbert, K. (2013). Learning analytics as a "middle space." Proceedings of the Third International Conference on Learning Analytics and Knowledge (LAK '13), 1-4. http://dx.doi.org/10.1145/2460296.2460298 
(2015). From theory use to theory building in learning analytics: A commentary on "Learning Analytics to Support Teachers during Synchronous CSCL". Journal of Learning Analytics, 2(2), 163-168. http://dx.doi.org/10.18608/jla.2015.22.12

Sweller, J. (1988). Cognitive load during problem solving: Effects on learning. Cognitive Science, 12(2), 257-285. http://dx.doi.org/10.1016/0364-0213(88)90023-7

Sweller, J., van Merrienboer, J. J. G., \& Paas, F. G. W. C. (1998). Cognitive architecture and instructional design. Educational Psychology Review, 10(3), 251-296. http://dx.doi.org/10.1023/A:1022193728205

Van de Ven, A. H. (1989). Nothing is quite so practical as a good theory. Academy of Management Review, 14(4), 486-489. http://dx.doi.org/10.5465/AMR.1989.4308370

Van Leeuwen, A. (2015, this issue). Learning analytics to support teachers during synchronous CSCL: Balancing between overview and overload. Journal of Learning Analytics, 2(2), 138-162. http://dx.doi.org/10.18608/jla.2015.22.11

Zimmerman, B. J. (1990). Self-regulated learning and academic achievement: An overview. Educational Psychologist, 25(1), 3-17. 